\title{
Study of Back Strength and Its Association with Selected Anthropometric and Physical Fitness Variables in Inter-university Hockey Players
}

\author{
Shyamal Koley, Santosh Jha and Jaspal Singh Sandhu \\ Department of Sports Medicine and Physiotherapy, Guru Nanak Dev University, \\ Amritsar 143005, Punjab, India
}

KEYWORDS Flexibility Measures. Abdominal Muscle Endurance. Back Strength. Anthropometric Characteristics

\begin{abstract}
The purpose of this study was of two-fold: first, to estimate the back strength of inter-university hockey players and, second, to search the correlation of it with selected anthropometric characteristics. To serve this purpose, a total of seven anthropometric characteristics, viz. height, weight, BMI, hip circumference, percent body fat, percent lean body mass and back strength and two physical fitness variables, viz. flexibility measures and abdominal muscle endurance were measured on purposely selected 110 inter-university hockey players (58 males and 52 females) aged 18-24 years collected from six universities participated in the Inter-university Championship organized in Guru Nanak Dev University, Amritsar, Punjab, India during 10 to 17 September, 2010. An adequate number of controls were also taken from the same place for comparisons. Results indicated significant differences $(\mathrm{p}<.05-.000)$ between hockey players and their control counterparts in weight, BMI, hip circumference (only in male players), flexibility measures, abdominal muscle endurance (both in male and female players), percent body fat and percent lean body mass (only in male players) and back strength (only in female players). In hockey players, back strength has significantly positive correlations $(\mathrm{p}<.05-.01)$ with all the variables studied (except flexibility measures).
\end{abstract}

\section{INTRODUCTION}

Hockey is an intermittent endurance sport involving short sprinting as well as movement with and without ball (Manna et al. 2009). Successful performance in hockey is influenced by morphological and anthropometric characteristics such as body size and composition, functional parameters (physical capacity) (Withers and Roberts 1981; Bale et al. 1986; Mokha and Sidhu 1987; Fedotova et al. 1990; Scott 1991; Seluyanov and Sarsaniya 1991; Singh et al. 2010) and fitness (explosive strength, maximum speed, anaerobic and aerobic capacity, agility) (Bril 1980; Volkov and Filin 1983; Ayrapetyanz and Godik 1991; Nikitushkin and Guba 1998). Studies relating to back strength of hockey players are less reported. As in hockey, players are to bend forward to the ground for the maximum groundwork and to cover a wider range all around during the game (Sodhi 1991) and maximum strain comes over the back muscles as well as abdominal muscles during the entire duration of the game. These back extensors get

Address for correspondence :

Dr. Shyamal Koley,

E-mail: drkoley@yahoo.co.uk, drskoley@gmail.com fatigued and sore as the game goes on. Although some players may have weakness in their back extensors, more often this discomfort is related to muscle imbalance. Muscle imbalance in hockey players may also result in sore or tight hips. The most common muscle imbalance in hockey players is tightness of the hip flexors. Thus, evaluation of back strength is essential to the hockey players not only for their maximal performance but to avoid the sports specific injuries too.

Strength can be defined as the maximum force which can be exerted against an immovable object (static or isometric strength), the heaviest weight which can be lifted or lowered (dynamic strength), or the maximal torque which can be developed against a pre-set rate-limiting device (isokinetic strength) (Thompson 1994; Roy and Pal 2001). Muscular strength, endurance and flexibility are important components of healthy back functions. A number of studies reveal that muscle strength is critical to health and well-being (McDonanghand Davies 1984; Astrand and Rodahl 1986). Several external factors, viz. altitude (Ruff and Strughold 1942), position of exerting strength (Teraoka 1979), diet (Keys et al. 1950) and internal factors, viz. age, sex (Mathiowetz et al. 1985), height, weight (Schimdt and Toews 1970) 
etc. influence the maximum force that can be exerted by a muscle (Berne and Levy 1983).

Though the importance of studying back strength is immense, literature related to back strength in hockey players is scanty, especially in Indian context. So the present study was planned. The objectives of the present study were to estimate the back strength of interuniversity hockey players, to study the gender differences on the basis of their back strength and to search any association of back strength with selected anthropometric and physical fitness variables among them.

\section{MATERIAL AND METHODS}

\section{Participants}

The present cross-sectional study is based on purposely selected 110 inter-university hockey players ( 58 males and 55 females) aged 18-25 years (mean age 18.82 years, \pm 1.91 ) of six universities, namely Punjab University, Chandigarh; Punjabi University, Patiala; Guru Nanak Dev University, Amritsar; Delhi University, Delhi; Kurukshretra University, Kurukshreta and Himachal Pradesh University, Shimla, participated in the Inter-university Championship organized in Guru Nanak Dev University, Amritsar, Punjab, India, during 10 17 September, 2010. An adequate number of controls $(\mathrm{n}=106,55$ males and 51 females, mean age 18.76 years, \pm 1.12 ) with no particular athletic background were also collected from the same place for comparisons. The age of the subjects were recorded from the date of birth registered in their respective records submitted to the organizers. The subjects were divided in such a way that age 18 refers to the individuals aged 17 years and 6 months through 18 years and 5 months and 29 days. A written consent was obtained from the subjects. The data were collected under natural environmental conditions in morning (between $8 \mathrm{AM}$. To 12 noon). The study was approved by the local ethical committee.

\section{Back Strength Measurement}

The back strength was measured using backleg-chest dynamometer. The subject was positioned with body erect and knees bent so that grasped-hand rests at proper height. Then straightening the knees and lifting the chain of the dynamometer, pulling force was applied on the handle. The body was inclined forward at an angle of 60 degrees. The strength of the back muscles was recorded on the dial of the dynamometer as the best of three trials in $\mathrm{kg}$. All subjects were tested after 3 minutes of independent warm-up. Thirty seconds time interval was maintained between each back strength testing.

\section{Anthropometric Measurements}

Seven anthropometric characteristics, viz. height, weight, BMI, hip circumference, percent body fat, percent lean body mass and back strength, and two physical fitness variables, viz. flexibility measures and abdominal muscle endurance were measured on each subject using standard techniques (Lohmann et al. 1988) and were measured in triplicate with the median value used as the criterion.

The height was recorded during inspiration using a stadiometer (Holtain Ltd., Crymych, Dyfed, UK) to the nearest $0.1 \mathrm{~cm}$. Weight was measured by digital standing scales (Model DS410, Seiko, Tokyo, Japan) to the nearest $0.1 \mathrm{~kg}$. BMI was then calculated using the formula weight $(\mathrm{kg}) /$ height $^{2}(\mathrm{~m})^{2}$. Hip circumference was measured using a flexible metallic tape (Holtain Ltd). Abdominal muscle endurance was recorded using 60 second sit up test in repetitions per minute. The same sit and reach test was used to estimate back and hamstring flexibility in inches. Percent body fat was assessed with standard formula (Womersely and Durnin 1977) using the four skinfold measurements (biceps, triceps, subscapular and suprailiac) measured with Harpenden skinfold caliper (Holtain Ltd, Crosswell, Crymych, UK) to the nearest $0.2 \mathrm{~mm}$. Percent lean body mass was calculated subtracting percent body fat from 100. The instruments were calibrated prior to use and all measurements were taken on the subject's right side.

\section{Statistical Analysis}

Standard descriptive statistics (mean \pm standard deviation) were determined for directly measured and derived variables. One way analysis of variance was tested for the comparisons of data among inter-university 
hockey players and controls (both males and females), followed by post hoc Bonferroni test. Pearson's correlation coefficients were applied to establish the relationships among the variables measured. Data were analyzed using SPSS (Statistical Package for Social Science) version 17.0. A $5 \%$ level of probability was used to indicate statistical significance.

\section{RESULTS AND DISCUSSION}

Descriptive statistics of anthropometric variables and back strength of inter-university hockey players and controls are shown in Table 1. Statistically significant $(\mathrm{p}<.05-.001)$ differences were noted between male hockey players and their control counterparts (not shown in the table) in weight $(\mathrm{t}=2.92)$, BMI $(\mathrm{t}=2.44)$, hip circumference $(\mathrm{t}=2.08)$, flexibility measures $(t=5.15)$, abdominal muscle endurance $(\mathrm{t}=9.53)$, percent body fat (3.44) and percent lean body mass $(\mathrm{t}=3.42)$, whereas highly significant differences $(\mathrm{p}<.000)$ were found between female hockey players and controls in flexibility measures $(\mathrm{t}=9.31)$, abdominal muscle endurance $(\mathrm{t}=8.96)$ and back strength $(\mathrm{t}=4.78)$. Highly significant $(\mathrm{p}<.01)$ sex differences were found in hockey players in height $(\mathrm{t}=10.44)$, weight $(\mathrm{t}=6.61)$, abdominal muscle endurance $(\mathrm{t}=6.31)$ and in back strength $(\mathrm{t}=17.28)$. One way ANOVA showed significant differences $(p<.01-.000)$ in all the characteristics studied among these four sets of data.

Correlation coefficients of the back strength and selected anthropometric and physical fitness characteristics were examined in inter-university hockey players in Table 2. In hickey players, back strength has significantly positive correlations $(\mathrm{p}<.05-.01)$ with all the variables studied (except flexibility measures).

Table 1: Descriptive statistics of various anthropometric variables among inter-university hockey players

\begin{tabular}{|c|c|c|c|c|c|c|c|c|}
\hline \multirow[t]{2}{*}{ Variables } & \multicolumn{2}{|c|}{$\begin{array}{c}\text { Hockey players } \\
\text { male }(n=58)\end{array}$} & \multicolumn{2}{|c|}{$\begin{array}{l}\text { Hockey players } \\
\text { female }(n=55)\end{array}$} & \multicolumn{2}{|c|}{$\begin{array}{c}\text { Control males } \\
(n=55)\end{array}$} & \multicolumn{2}{|c|}{$\begin{array}{c}\text { Control females } \\
\quad(n=51)\end{array}$} \\
\hline & Mean & $S . D$ & Mean & S.D & Mean & S.D & Mean & S.D \\
\hline Height $(\mathrm{cm}){ }^{* *}$ & 172.32 & 4.84 & 161.89 & 5.14 & 172.20 & 7.37 & 160.77 & 4.89 \\
\hline Weight $(\mathrm{kg}){ }^{* *}$ & 62.32 & 6.46 & 53.69 & 6.57 & 68.24 & 12.79 & 53.22 & 8.66 \\
\hline $\begin{array}{l}\text { Body Mass Index } \\
\left(\mathrm{kg} / \mathrm{m}^{2}\right)^{* *}\end{array}$ & 20.97 & 1.81 & 20.44 & 1.95 & 22.94 & 3.63 & 20.61 & 3.39 \\
\hline $\begin{array}{l}\text { Hip circumference } \\
(\mathrm{cm})^{*}\end{array}$ & 91.16 & 5.28 & 89.55 & 5.95 & 93.84 & 7.42 & 91.07 & 7.11 \\
\hline $\begin{array}{l}\text { Flexibility measure } \\
\text { (inches) }\end{array}$ & 13.09 & 3.44 & 14.18 & 1.94 & 9.18 & 4.11 & 9.13 & 3.30 \\
\hline $\begin{array}{l}\text { Abdominal muscle } \\
\text { endurance (rep) }\end{array}$ & 47.00 & 8.20 & 38.32 & 5.23 & 33.00 & 6.37 & 27.80 & 6.44 \\
\hline $\begin{array}{l}\text { Percent body } \\
\text { fat }(\%)^{* *}\end{array}$ & 20.26 & 2.48 & 22.54 & 2.68 & 24.96 & 4.97 & 27.77 & 4.65 \\
\hline $\begin{array}{l}\text { Percent lean body } \\
\text { mass }(\%)^{* * *}\end{array}$ & 79.74 & 2.48 & 77.46 & 2.67 & 75.04 & 4.97 & 72.23 & 4.64 \\
\hline Back strength $(\mathrm{kg})^{* *}$ & 60.57 & 14.02 & 18.65 & 9.87 & 54.75 & 18.69 & 9.90 & 8.39 \\
\hline
\end{tabular}

*Significant at .05 level; ${ }^{* *}$ Significant at .000 level

Table 2: Correlation coefficient of back strength and selected anthropometric variables in interuniversity hockey players and controls

\begin{tabular}{|c|c|c|c|c|}
\hline \multirow[t]{2}{*}{ Variables } & \multicolumn{2}{|c|}{ Hockey players } & \multicolumn{2}{|c|}{ Controls } \\
\hline & $r$ & $p$ & $r$ & $p$ \\
\hline Height $(\mathrm{cm})$ & .64 & $\mathrm{P}<0.01$ & .71 & $\mathrm{P}<0.01$ \\
\hline Body weight $(\mathrm{kg})$ & .63 & $\mathrm{P}<0.01$ & .71 & $\mathrm{P}<0.01$ \\
\hline B.M.I. $(\mathrm{kg} / \mathrm{m} 2)$ & .33 & $\mathrm{P}<0.01$ & .46 & $\mathrm{P}<0.01$ \\
\hline Hip circumference $(\mathrm{cm})$ & .21 & $\mathrm{P}<0.05$ & .35 & $\mathrm{P}<0.01$ \\
\hline Flexibility measure (inches) & .04 & NS & .14 & NS \\
\hline Abdominal muscle endurance (rep) & .67 & $\mathrm{P}<0.01$ & .43 & $\mathrm{P}<0.01$ \\
\hline Percentage body fat $(\%)$ & .33 & $\mathrm{P}<0.01$ & .46 & $\mathrm{P}<0.01$ \\
\hline Percent lean body mass $(\%)$ & -.33 & $\mathrm{P}<0.01$ & -.46 & $\mathrm{P}<0.01$ \\
\hline
\end{tabular}


As compared to most other sports, hockey is a short-distance sport where running means mostly sprinting, and the sprinting-distances vary from only a few meters to not more than 50 or $60 \mathrm{~m}$. Therefore, quickness, explosive strength and agility are the characteristics that significantly influence performance in hockey. It is reported that a battery of anthropometric and morphological tests can distinguish between players of different ability in the same sport (Keogh 1999). The same is true for the hockey (Reilly et al. 1990; Scott 1991; Reilly and Borrie 1992; Manna et al. 2009; Singh et al. 2010). In the present study, significant differences $(\mathrm{p}<.05$ $.000)$ were noted between hockey players and their control counterparts in weight, BMI, hip circumference (only in male players), flexibility measures, abdominal muscle endurance (both in male and female players), percent body fat and percent lean body mass (only in male players) and back strength (only in female players). These differences were probably due to the effect of regular physical exercise and strenuous training program in hockey players. Highly significant $(\mathrm{p}$ $<$.01) sex differences were found in hockey players in height, weight, abdominal muscle endurance and in back strength. Physical and physiological factors might be the reasons for these differences, where male players were taller and heavier, also more muscular due to the presence of testosterone hormone in them. More musculature generates more force in their back region. Differences in mode of training programs in hockey players of these two sexes might be another reason.

In the present study, strong correlations of back strength with all the anthropometric and physical fitness characteristics studied (except flexibility measures), showed structural and physiological affinity towards the back strength. It was reported earlier too, that several anthropometric variables were strongly correlated with back strength in different populations (Roy and Pal 2001). In the present study those anthropometric variables were considered which were not reported earlier for the study of correlations with back strength. More anthropometric variables should be taken into consideration for this purpose in future studies.

The data presented in the present study carry immense practical applications and should be useful in future investigation on player selection, talent identification in field hockey and training program development.

\section{REFERENCES}

Astrand PO, Rodahl K 1986. Textbook of Work Physiology: Physiological cases of Exercise. $2^{\text {nd }}$ Edition. New York: McGraw-Hill Inc.

Ayrapetyanz LR, Godik MA1991. Sports Games. Tashkent: IbnSina Press.

Bale P, McNaught-Devis P 1983. The physique, fitness and strength of top class women hockey players. Journal of Sports Medicine and Physical Fitness, 23: $80-88$.

Berne RM, Levy MN1983. Physiology. St. Louis, MO: CV Mosby Co.

Bril MS 1980. The Selection of Games. Moscow: Physical Culture and Sports. Moscow,

Fedotova EV, Bril MS, Martirosov EG1990. Element of morpho-function model of elite female field hockey players (review). Scientific Sport Bulletin, 2: 29-33.

Keogh J 1999. The use of physical fitness scores and anthropometric data to predict selection in an elite under-18 Australian rules football team. Journal of Sport Science and Medicine, 2: 125-133.

Keys A, Mickelsen O, Miller EO, Chapman CB 1950.The relation in man between cholesterol levels in the diet and in the blood. Science, 112:79-81.

Lohmann TG, Roche AF, Martorell R1988. Anthropometric Standardization Reference Manual. Champaign, IL: Human Kinetics Books.

Manna I, Khanna GL, Dhara PC 2009. Training induced changes on physiological and biochemical variables of young Indian field hockey players. Biology of Sport, 26(1): 33-43.

Mathiowetz V, Rennells C, Donahoe L 1985. Grip and Pinch strength: Normative data for adults. Archives for Physical Medicine and Rehabilitation, 66: 6974.

McDonangh MJN, Davies CTM1984. Adaptive response of mammalian skeletal muscle to exercise with high loads. European Journal of Applied Physiology, 52: 139-155.

Mokha R, Sidhu LS 1987. Body fat in various sportive groups. Journal of Sports Medicine and Physical Fitness, 27: 376-379.

Nikitushkin VG, Guba VP 1998. Methods of Selection in Team Sports. Moscow: IKAP Press.

Reilly T, Borrie A 1992. Physiology applied to field hockey. Sports Medicine, 14: 10-26.

Reilly T, Secher N, Snell P, Williams C 1990. Physiology of Sports. London: E. and F.N. Spon.

Roy SK, Pal B2001. Factors influencing back strength and the changes due to age of the Oraon agricultural labourers of the Jalpaiguri District, West Bengal. International Journal of Anthropology, 16(4): 263273.

Ruff S, Strughold H 1942. Compendium of Aviation Medicine.WADC Technical Report 14. OH. WrightAir Development Center, Air Research and Development Command. United States Air Force, pp. 32-34. 
Schimdt RT, Toews JV 1970. Grip strength as measured by Jamar Dynamometer. Archives for Physical Medicine and Rehabilitation, 51: 321-327.

Scott PA 1991. Morphological characteristics of elite male field hockey players. Journal of Sports Medicine and Physical Fitness, 31: 57-61.

Seluyanov VN, Sarsaniya SK 1991.Conditioning in Team Sports (Field Hockey, Soccer, Ice Hockey). Moscow: RSAPE Press.

Singh M, Singh MK, Singh K 2010. Anthropometric measurements, body composition and physical parameters of Indian, Pakistani and Sri Lankan field hockey players. Serbian Journal of Sports Sciences, 4(2): 47-52.

Sodhi HS 1991.Sports Anthropometry. Mohali: ANOVA Publications.
Teraoka T 1979. Studies on the peculiarity of grip strength in relation to body positions and aging.Kobe Journal of Medical Sciences, 25:1-17.

Thompson LV 1994. Effects of age and training on skeletal muscle physiology and performance. Physical Thermodynamics, 74: 71-81.

Volkov VM, Filin VP 1983. Sport Selection. Physical Culture and Sport, Moscow.

Withers RT, Roberts RGD 1981. Physiological profiles of representative women softball, hockey and netball players. Ergonomics, 24: 583-591.

Womersely J, Durnin JUGA 1977.A comparison of the skinfold method with extent of "overweight" and various weight height relationships in the assessment of obesity. British Journal of Nutrition, 38: 271-284. 